\title{
European Doctoral Programs in Light of EHEA and ERA
}

\author{
Nicola Vittorio
}

\section{The European Area of Higher Education}

When fifteen years ago, in 1998, on the occasion of the 800th anniversary of the founding of the University of Paris, four European ministers of education-Claude Allegre (France), Luigi Berlinguer (Italy), Tessa Blackstone (UK) and Jurgen Ruttgers (Germany) - agreed on what is by now known as the Sorbonne Declaration, perhaps a few believed in the political impact that this statement would have had. It was that statement, however, that encouraged member states to adopt a common framework to facilitate diploma recognition and to incentivize student mobility, as well as their employability. In other words, it is the constitutive act of the European Higher Education Area-EHEA that today, 15 years later, sees the participation of 47 countries, obviously not all belonging to the European Union. This provides, by itself, independently of any considerations on the actual implementation of the reform, the measure of the success of the idea behind the Sorbonne declaration.

Almost in parallel, in the year 2000, the idea of a European Research AreaERA started to have a formally definite framework with the European Commission's Communication COM (2006) "Toward a European Research Area", ${ }^{1}$ even if a good part of the elements at the base of this idea can be found in the book "A European Area of Science" by the former Commissioner for research, Antonio Ruberti, written with Michel Andre in 1994. The idea of an ERA is by now

\footnotetext{
${ }^{1}$ http://ec.europa.eu/research/era/pdf/com2000-6-en.pdf.

N. Vittorio $(\bowtie)$

Physics Department, University of “Tor Vergata”, Rome, Italy

e-mail: nicola.vittorio@uniroma2.it

(C) The Author(s) 2015

A. Curaj et al. (eds.), The European Higher Education Area,

DOI 10.1007/978-3-319-20877-0_35
} 
formalized in the Consolidated Version of the Treaty on the Functioning of the European Union-TFEU. ${ }^{2}$ In fact, the Article 179 - first paragraph — of the TFEU reads as follows: "The Union shall have the objective of strengthening its scientific and technological bases by achieving a European research area in which researchers, scientific knowledge and technology circulate freely, and encouraging it to become more competitive, including in its industry, while promoting all the research activities deemed necessary by virtue of other Chapters of the Treaties."

Clearly, doctoral programs position themselves in the overlapping region of these two big European Areas, Higher Education and Research, as they complete the educational process of an individual with a training to research through research that opens the doors to a research career in the public and private sectors. In these years, both in the EHEA and in the ERA, ideas, proposals and documents on doctoral programs have been produced. In the meantime, other important stakeholders, as $\mathrm{EUA}^{3}$ and LERU, ${ }^{4}$ have worked on the issue from the side of higher education Institutions. Thus, the purpose of this paper is as follows. In Sect. 2 I will briefly review the European view on doctoral training. In Sect. 3 I will report the findings of the ad hoc working group on the III cycle constituted by the Bologna Follow-Up Group-BFUG ${ }^{5}$ in view of the meeting in 2015 at Yerevan of the EHEA Ministers of Education. In Sect. 4, I will present a discussion on and the results of the recent Italian reform of doctoral programs. In Sect. 5, I will report on two initiatives dedicated to doctoral programs and promoted during the semester of Italian Presidency of the EU. Finally, in Sect. 6, I will summarize the main points of the current discussion.

\section{The Third Cycle of Tertiary Education}

Doctoral programs explicitly entered in the EHEA only in 2003. In fact, the so-called Berlin Communiqué ${ }^{6}$ states the necessity to go beyond the two cycle structure suggested by the Sorbonne declaration and to include doctoral programs in a third cycle of tertiary education. This is an important point, even if it is not always shared, as it identifies doctoral programs as the more valuable segment of tertiary education, acknowledging at the same time its fundamental and indispensable characteristic: training to research through research.

\footnotetext{
${ }^{2}$ http://eur-lex.europa.eu/legal-content/en/ALL/ELX_SESSIONID=tkkvJV1GGG9vKwzFsx3nVt R4F9ZPTsPJMDSQt1VIVHpHQJQTybWw!-1279509169?uri=CELEX:12012E/TXT.

${ }^{3}$ www.eua.be.

${ }^{4}$ www.leru.org.

${ }^{5}$ The working group on the III cycle was created in the framework of a wider working group on the structural reforms for the implementation of the Bologna Process.

${ }^{6}$ www.ehea.info/Uploads/about/Berlin_Communique1.pdf.
} 
This attention to doctoral training and to its quality as a fundamental step to foster research and innovation - and, therefore, to aim to an economic development that must be sustainable, equitable and inclusive - is followed up by the Bergen Communiqué $^{7}$ of 2005. It is interesting to realize that most of the architectural elements for a deep and modern reform of doctoral programs where already in that Communiqué: (i) the alignment of the third cycle with the overarching Framework of Qualifications for the EHEA; (ii) the development of structured doctoral programs, fully transparent in their enrolment and supervision procedures; (iii) a duration of doctoral programs that corresponds to three, maximum four years for a full-time doctoral candidate; (iv) a specific focus by universities on the employability of their doctoral candidates, by providing interdisciplinary training and the acquisition of transferable skills, such as communication, ability to work in a group, project management, self-entrepreneurship, etc.; (v) the maintenance of a double legal status that, considering different country traditions and regulations, sees the doctoral candidate both as a student and as an early stage researcher; (vi) an increase in the number of doctoral candidates to involve them, ever more effectively, in careers related to research, both in the public and in the private sectors. This is an architectural design that assigns to the doctoral programs a central role for Europe to become a leading knowledge-based society.

After Bergen, there are at least three other important contributions from relevant stakeholders that it is worth to mention in this brief account.

EUA promoted with its Council for Doctoral Education an independent reflection on the role of doctoral programs and on their organization, suggesting ways to improve both the process - research training through research - and the product- "innovators" capable of transferring science and technology with their own legs from the universities to the productive world. The results of this reflection constitute the so-called Salzburg Principles ${ }^{8}$ and, later on, the Salzburg II Recommendations. ${ }^{9}$ Principles and Recommendations that help in configuring an innovative, European doctoral program, calling for a stronger institutional involvement in developing policies for recruitment, supervision and thesis evaluation, and emphasizing the vital role of the doctoral candidate mobility, in all its possible dimensions: geographical mobility, intra- or inter-disciplinary mobility and/or inter-sectorial mobility.

In 2005, the European Commission released two documents, the European Charter for Researchers and the Code of Conduct for the Recruitment of Researchers ${ }^{10}$ with recommendations that are aimed to render doctoral training really competitive by: (i) giving particular attention to the working conditions and the training of doctoral candidate; (ii) creating a system of recruitment and career development that is transparent, open, and internationally recognized;

\footnotetext{
${ }^{7}$ http://www.ehea.info/Uploads/Declarations/Bergen_Communique1.pdf.

${ }^{8} \mathrm{http}: / /$ www.eua.be/cde/publications.aspx.

${ }^{9}$ http://www.eua.be/cde/publications.aspx.

${ }^{10} \mathrm{http}: / /$ ec.europa.eu/euraxess/index.cfm/rights/brochure.
} 
(iii) overcoming every residual obstacle to the geographical and inter-sectorial mobility, as well as the mobility between different functions within the same institution; (iv) considering doctoral candidate as professionals that must be treated as such since the very initial phase of their career.

More recently, the ERA Steering Group on Human Resources and MobilitySGHRM $^{11}$ developed and presented the Principles of Innovative Doctoral Training-PIDT ${ }^{12}$ : (i) research excellence; (ii) attractive institutional environment; (iii) interdisciplinary research options; (iv) exposure to industry and other relevant employment sectors; (v) international networking; (vi) transferable skills training; (vii) quality assurance. In particular, the "triple I" approach was promoted: a doctoral program should be international, inter-disciplinary and inter-sectorial to be really innovative. It is worth mentioning here that the European Commission, DG Research and Innovation, has recently commissioned a study to explore the implementation of the Innovative Doctoral Training Principles, to monitor existing barriers and to provide recommendations to foster the PIDT implementation. According to the study, the main barriers are connected to the economical situation-low doctoral candidate salaries that force them to enrol as part-time candidate and/or prevent them from going abroad; the lack of knowledge-intensive industries around the institution, or industries that are not prepared to integrate doctoral candidates at an appropriate level —or to the political/legislation situation - in a few countries existing legislation and accreditation criteria that do not support interdisciplinary programs. In a more recent document, ${ }^{13}$ not all the seven PIDT are regarded as equally important: research excellence, quality assurance and attractiveness of the research environment are considered as basic principles; the triple I approach and the transferable skills training are considered important, but only as a complement to the basic principles.

Finally the last Communiqué of EHEA Ministers of Education was released in Bucharest in 2012. The Bucharest Communiqué ${ }^{14}$ reaffirms the need to reach automatic recognitions of academic degrees issued within the EHEA, acknowledges the EUA and the SGHRM documents, and sets as strategic goal for 2015 four specific aspects of doctoral programs: quality, transparency, employability and mobility. Ministers expect from experts and stakeholders recommendations to guide the design, the implementation and the evaluation of those doctoral programs that want to qualify themselves as Europeans and innovative.

\footnotetext{
${ }^{11}$ The SGHRM is the structure to support the implementation and monitoring of progress of the Innovation Union Flagship Initiative (IU) and the development of its ERA Framework in the areas related to researchers' career, training and mobility as well as the attractiveness of Europe to researchers in general.

${ }^{12} \mathrm{http}: / /$ ec.europa.eu/euraxess/pdf/research_policies/Principles_for_Innovative_Doctoral_Training. pdf.

${ }^{13} \mathrm{http}: / /$ ec.europa.eu/euraxess/pdf/research_policies/SGHRM_IDTP_Report_Final.pdf.

${ }^{14}$ www.ehea.info/Uploads/(1)/Bucharest\%20Communique\%202012(2).pdf.
} 


\section{The BFUG Ad Hoc WG on the III Cycle}

The Bologna Follow-Up Group decided to develop the policy recommendation set by Ministers in the Bucharest Communiqué by setting up, in August 2012, an ad hoc working group on the III cycle- $-\mathrm{WG}_{\text {IIIcycle, }}{ }^{15}$ as a sub-structure of its Structural Reform Working Group-SRWG. The mandate of the $\mathrm{WG}_{\text {IIIcycle }}$ was to map the current implementation of the third cycle in the EHEA and to formulate policy proposals: (i) to promote quality, transparency, employability and mobility in the third cycle, taking into account the developments foreseen within the ERA by Horizon 2020 and other EU initiatives; (ii) to improve the transition between the second and the third cycle, with the aim to strengthen the link between education and research. The $\mathrm{WG}_{\mathrm{IIIcycle}}$ was also required to make other policy proposals related to the third cycle, such as sustainable funding for third cycle education or candidate recruitment practices.

The $\mathrm{WG}_{\text {IIIcycle }}$ has delivered its report to the SRWG in the summer 2014. The report contains the results of the mapping of the implementation of the Salzburg Recommendations and of the Principles for Innovative Doctoral Training, summarizing the main developments in Doctoral training, with a specific focus on institutional strategies for structured training, exposure to the private sector, employability, mobility and internationalization. The report also discusses, focusing on doctoral programs, the achievement in the introduction of qualifications frameworks, of transparency instruments and of quality assurance. The report finally discusses, proposing recommendations on further improvements, the achievements and the impact of the policies done at institutional, national and European levels on the innovation of doctoral programs, employability, internationalization and mobility. Upon recommendation of the Structural Reform working group, the report will be discussed by the Bologna Follow Up Group directly.

As already mentioned, at their Bucharest meeting, EHEA Ministers of Education asked for policy recommendation on how to improve quality, transparency, employability, internationalization and mobility in the third cycle. The discussion

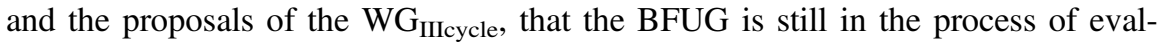
uating, can be briefly summarized as follows.

\footnotetext{
${ }^{15}$ The $\mathrm{WG}_{\text {IIIcycle }}$ - co-chaired by representatives of Italy, Romania and Spain — has met five times (in Rome in December 2012, in Bucharest in May 2013, in Madrid in October 2013, in Bucharest in February 2014 and in Rome in May 2014). The membership of the group includes Armenia, Austria, Belgium/Flemish Community, Belgium/French Community, Croatia, the Czech Republic, Denmark, France, Germany, the Holy See, Hungary, Ireland, Moldova, Poland, Ukraine, United Kingdom, the European Commission, the EUA, EI, and EURODOC.
} 


\subsection{Quality in Doctoral Training}

The $\mathrm{WG}_{\text {IIIcycle }}$ adopted the definition of a doctoral program as training to research through research. This is perfectly in line with the Berlin Communique where EHEA Ministers have commonly agreed that "The core component of doctoral training is the advancement of knowledge through original research". This might sound obvious for most of the people working in the Academia, although different disciplines may have different understanding and different approaches. So, while it is important to push for innovative doctoral training, it must also acknowledge the long standing tradition of doctoral education in Europe. It is in this tradition the idea that a $\mathrm{PhD}$ graduate should be a competent and skilled researcher, qualified for a further career in, as well as outside, academia. Also, it is in this tradition a careful evaluation of the research production. So, traditional doctoral programs can be innovative as they introduce innovative features to both research training and research outputs. In this sense, it is generally believed that an expansion of the training dimension of the third cycle to interdisciplinary issues and the acquisition of transversal skills is very rewarding for both the quality of the research and the doctoral candidates' employability. Thus, all doctoral programs should provide: (i) a supportive and inclusive research environment based on good supervision; (ii) a direct involvement of doctoral candidates in improving the overall quality of the program; (iii) the use of independent and external peer review to assess outcomes such as originality, creativity and independence through the $\mathrm{PhD}$ thesis defence; (iv) the provision of internal quality assurance procedures about the supervision process and the candidates' training. Therefore, the $\mathrm{WG}_{\text {IIIcycle }}$ proposed for Ministerial consideration several guidelines that should be included in the national quality assurance framework for the third cycle. In addition, at EHEA level, quality assurance frameworks for doctoral cycle should encourage the assessing agencies to take into account the European Standard Guidelines, the reference documents and the standpoints on doctoral training that the EHEA Ministers agreed upon in Bergen ${ }^{8}$, in addition to any other relevant ministerial commitments. Furthermore, in order to enhance a meaningful link between the second and third cycle, the $\mathrm{WG}_{\text {IIIcycle }}$ considered important sparking interest of students towards research already in the II cycle, by supporting those second cycle programs based on learning outcomes directly related to research. The $\mathrm{WG}_{\text {IIIcycle }}$ suggests the implementation of tools that facilitate the transition from the second to the third cycle for those students which are particularly talented and inclined towards research.

\subsection{Development of Transparency Tools}

The discussion on transparency tools for the third cycle focused on two issues, the Diploma Supplement-DS and the use of ECTS. The $\mathrm{WG}_{\text {IIIcycle }}$ concluded that a 
DS - in the European format developed according to the European Commission, the Council of Europe and UNESCO guidelines - should be available also in a widely spoken European language and it should be issued automatically and free of charge to all Doctoral graduates across the EHEA. The DS is not a PhD holder CV, but rather it includes the doctoral program description, specific learning activities, thesis title and assessment, as well as mobility experiences, transferable skills, international cooperation activities and/or research projects the student has been involved in.

On ECTS, $\mathrm{WG}_{\text {IIIcycle }}$ did not reach consensus because of the diversity of positions of the EHEA countries on this issue. The "contra" arguments focused on the use of ECTS in the III cycle as it could generate a 'race for credit', which is seen as detrimental to the main purpose of the third cycle - training to research through research. The other dissenting argument was that the 'intended learning outcomes' at doctorate level cannot be as specifically defined as they can be in the first and second cycles, given the dominance of the research activities. On the other hand, when applied, ECTS could facilitate assessment mechanisms, help in monitoring the distribution of the workload for the candidate and could contribute to enhancing mobility for the third cycle. Also, the use of ECTS should facilitate the issuing of a certification for those doctoral candidates that interrupt their studies or need valorisation outside of the academia of the skills acquired. The $\mathrm{WG}_{\text {IIIcycle }}$ finally agrees that the decision of using ECTS in the III cycle should be left to the national context and to the institutional preferences. This seems a sensible position, very respectful of the university autonomy.

\subsection{Employability of Doctoral Graduates}

The outcome of doctoral programs should always be a $\mathrm{PhD}$ holder with a high level of research competences and a broad set of skills that help to develop his/her potential inside and outside the academic sector. To reach these goals, the existing diversifications of doctoral programs should be further increased. Collaborations in Doctoral training between institutions and the non-academic sector, interdisciplinary programs, structured programs and promotion of self-employment and entrepreneurship, must become the practice of higher education institutions. However, without a social awareness of the added value of a $\mathrm{PhD}$ holder for social progress and advancement in knowledge, innovation and productivity, we run the risk of returning to an old paradigm, doctoral programs suited only for the academia. Thus, Governments and both public and private institutions should provide more attractive, and socially recognized, career path for doctorate holders. This is the only way for promoting talents and spreading excellence. 


\subsection{Internationalization and Mobility}

It is difficult to underestimate the importance of mobility for doctoral candidates. The $\mathrm{WG}_{\text {IIIcycle }}$ stresses the importance of the geographical, as well as of the inter-sectorial mobility. The $\mathrm{WG}_{\mathrm{IIIcycle}}$ believes that Countries and the HEIs participating to the EHEA should fully implement existing and future recommendations on mobility, by adapting them to the research-based approach of Doctoral training. HEIs should be encouraged to develop programs with international partners. This is an opportunity to increase the number of scientific collaborations and, then, to further diversify and enrich the different academic environments. Last but not least, the $\mathrm{WG}_{\text {IIIcycle }}$ believes that data collection on international mobility of doctoral candidates shall be improved. In order to further evidence-based policies on Doctoral training and mobility, the $\mathrm{WG}_{\mathrm{IIIcycle}}$ believes that Ministers and HEIs should make an effort to collect more information and address statistical offices to coordinate data collection at the European level. The data collection should refer to the offered Doctoral programs, to the number of candidates and their profile, to candidates' international mobility and to Doctorate holder's employment.

\subsection{Funding}

In order to ensure the sustainable development of the third cycle across EHEA countries, $\mathrm{WG}_{\text {IIIcycle }}$ believes that Ministers should commit to guarantee sustainable funding for building the research capacity of universities. In this sense, the appropriate budget for research should be allocated primarily from public funds, while assuring transparent systems of funds' allocation. European level funding for doctoral programs should be awarded where a European added value can be demonstrated and should not be used to replace national public investments. The $\mathrm{WG}_{\text {IIIcycle }}$ recommends the balance between strategic or targeted funding and independent funding (contributing to operational support), while raising the capacity to attract funds either from private or public source. Additional solutions rest on supporting and incentivizing collaborative, innovative doctoral programs with partnerships that contribute to the diversification of income. At the same time, it is important to promote and implement a legal framework that ensures the independence of institutions receiving the money and the preservation of academic principles in research activities, especially when a private partnership is concerned.

\section{Doctoral Programs: What for?}

It's interesting to note how in the last 10 years, the majority of OECD countries have invested in doctoral programs, in line with the idea that in a knowledge society the training of innovators will result in a greater competitiveness in research and 
development. To reach this goal it is necessary to provide the best training and to ensure that the doctoral candidates are equipped with the most competitive skills. This is in line with the $\mathrm{WG}_{\text {IIIcycle }}$ recommendations, as well as with most of the documents produced in recent years from the Commission and from other stakeholders. However, to really diffuse research and innovation at all levels in the society, it is necessary a coordinated and sustainable effort to attract talents and direct them toward all the careers related to the world of research, be it public or private.

It must be remembered that more than $50 \%$ of $\mathrm{PhD}$ graduates find and will find jobs outside the university and public research bodies. Thus, there is a need, as already discussed in Sect. 3, for a diversification of the offer that could open, without distorting its essence, the training of doctoral candidate to the non-academic world. There are many examples in Europe of virtuous interaction between university and the labour market. For example in Denmark, there is a long tradition of the so-called industrial doctorates, that is doctoral programs that, under the control of quality of the universities, address research problems of interest for companies/industries. Obviously, this requires the existence of high-tech industries interested in promoting research and development in collaboration with the universities and research institutions. It also requires specific actions to promote this short circuit, not forgetting that this openness to non-academic sectors must apply not only to scientific-technological doctoral programs, but also to the ones in the field of humanities and social sciences.

Then, it is not surprising that the European Commission has promoted the European Industrial Doctorates under the Marie Sklodowska Curie actions, as well as the European Institute of Innovation and Technology (EIT) ${ }^{16}$ to create a structured collaboration between High Education Institutions and the non-academic sector to improve the innovation process by passing from the laboratory to the market, from the idea to the product, from a student to an entrepreneur. All this reinforces the idea that the doctoral programs are not only oriented to the academic career, but also to employment opportunities outside the academia, where the acquired skills are properly used and recognized. This was already discussed in 2003 in the EC Communication "Researchers in the ERA: one profession, multiple careers", where there were analysed the different elements that characterize the researcher profession and defined the various factors that affect the development of the careers of researchers at the European level: the role and the nature of the research training; the differences in the methods of recruitment; the contractual and economic aspects; the evaluation mechanisms; the prospects for progress in academic careers. While the quality and transparency discussed in Sect. 3 are mostly under the responsibilities of Higher Education Institutions (HEI), mobility and employability require a better connection with other non-academic sectors, both public and private. In fact, the concept of mobility should also be interpreted as the inter-sectorial mobility from HEI's to the private sector, and vice versa. It is this

\footnotetext{
${ }^{16}$ http://eit.europa.eu/about-us/.
} 
mobility that can reinforce a mutual trust between HEI's and R\&D oriented enterprises, in order to implement a real technological transfer and increase the employability of doctorate holders in sectors of the job market different from the traditional academic ones.

The priorities of the Italian Presidency of EU in the second semester of 2014 were shaped in line with "Horizon 2020 Italia"-HIT2020, the first strategic document approved by a Member State that has aligned the national research program with the Horizon 2020 priorities. In particular, in the Program of the Italian Presidency of the Council of the European Union, the European Research Area is mentioned in different sections, under Competitiveness, ${ }^{17}$ under Research and Innovation $^{18}$ and under Migration. ${ }^{19}$ So, it is not surprising that one of the Conferences organized during the Semester of Italian Presidency focuses on the "Empowerment of the Next Generation of Researchers: Promoting talents, spreading excellence". ${ }^{20}$ This conference aimed to address a number of issues that are really at the heart of the ERA, such as the feasibility of a truly open European labour market for researchers or the training of the scientific workforce in dialogue with industry, at least in some specific disciplines. Clearly, to achieve the economic and societal goals of Europe 2020 requires unlocking the full potential of new researchers. This requires strong and competitive national research systems embedded into a truly integrated European Research Area, where empowered talented researchers - either early stage or experienced - can circulate freely in an open, transparent, equitable and merit-based single labour market, as suggested by the European Parliament initiative for A Maastricht for Research ${ }^{21}$ of October 2013. In this Manifesto, seven priorities and key-actions were indicated; one of them was about "A European Research career". Regarding this point the document says: "The attractiveness of a research career, at every stage should be boosted. The mobility of researchers is essential for the realization of a future generation of

\footnotetext{
${ }^{17}$ “'Competitiveness is also closely linked to innovation and knowledge. Supporting the implementation of Horizon 2020, removing the bottlenecks to a real mobility of researchers in the European Research Area and better aligning national research priorities will be at the core of the Presidency agenda to help maintain a competitive edge and economic growth."

18“"Bearing in mind that the establishment of an authentic European Research Area is important for maintaining the European research systems on the leading edge of the advancement of knowledge, the Presidency will address this topic, taking into account the anticipated Second Annual ERA Progress Report by the Commission, with a view to adopting Council conclusions. Special emphasis will be given to boosting political commitment to joint EU research programming, with the aim of visibly reducing fragmentation and eliminating unnecessary duplication, as well as promoting the ERA's human resources component, and in particular the next generation of researchers."

19"In this context, the Presidency intends to continue, in particular, its efforts to define a proposal for a Directive of the European Parliament and of the Council on the conditions of entry and residence of third-country nationals for the purposes of research, study, pupil exchange, remunerated and unremunerated training, voluntary service and au pairing."

${ }^{20} \mathrm{http} / / / \mathrm{www} . \mathrm{msca} 2014$. eu/programme/.

${ }^{21}$ https://www.researchitaly.it/uploads/7892/Maastricht_ricerca.pdf.
} 
European researchers. Consequently, it has to be facilitated through the implementation of a set of appropriate measures, such as portability of national grants, coordinated systems of social security, transparent publication of competitions, implementation of the Charter and Code of Conduct for researchers etc. All researchers, including early stage researchers/doctoral candidates, have to be recognised for the contribution they give and treated as professionals in every EU country. Member States should endeavour to create recruitment and employment conditions of researchers more and more comparable in order to achieve the long term goal of a single European system."

The implementation of the European Research Area has required and still requires a wide and strong partnership between European institutions (Commission, European Parliament), Member States (with their Ministries for Research, for Foreign Affairs and for Welfare, as well as Universities, research funding and performing Organizations and private sector) and research stakeholder organizations. Unfortunately, the progresses have been strongly uneven across the different ERA dimensions, particularly in knowledge dissemination practices and research career conditions and prospects, resulting in an overall brain drain rather than in a more equal brain circulation. In any case, it is crucial to move rapidly form the architectural design (the European Research Area) to the actual implementation phase (The European Researchers' Area).

\section{The Italian Way to Doctoral Programs}

Doctoral programs were introduced in Italy only 30 years ago, with the aim of introducing a new academic title useful in an academic context. In fact, this title was (and still is) awarded as a result of a post-lauream research activity that provided original contributions to knowledge in mono- or pluri-disciplinary sectors. Thus, before the implementation of the Bologna process, doctoral programs were producing very qualified $\mathrm{PhD}$ holders for an academic career, definitely overqualified for a career outside academia. Even after the implementation of the Bologna Process, doctoral programs aimed at cultivating young talents, with employment opportunities mostly in Universities and public Research Institutions. This is why doctoral programs were (are) very little known and acknowledged on the labour market. In other words, the doctoral programs have been, and unfortunately still are, considered as the first level of the academic career, rather than the third level of the tertiary training. As mentioned in the previous section, there is a lot to do to overcome the widespread mistrust of companies and industries and to convince the private sector that $\mathrm{PhD}$ holders are not only researchers able to implement that technology transfer that everybody is looking for, but also innovators that can be usefully coopted by the private sector, as well as in the framework of the public administration.

In Italy, the Bologna Process was implemented in 2001. Thus, "Bologna" students could enter in a doctoral program only in 2006 or afterwards. The number of 


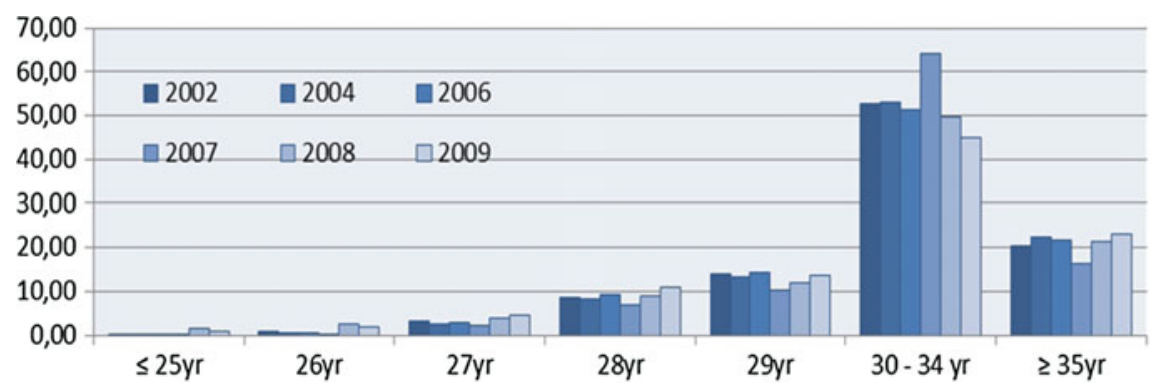

Fig. 1 Age distribution of $\mathrm{PhD}$ holders as a function of the year in which the title was awarded. Data from the statistical office of the Italian Ministry of Education, University and Research

enrolments to Italian doctoral programs has stabilized in the recent years, and now there are about 11,000-12,000 fellowships per year. In 2009, the Italian graduation rate $^{22}$ was almost at the $1.5 \%$ level (with a growth by a factor of 3 with respect to the year 2000), but still less than in England (2\%), Germany (2.5\%) and Sweden (3\%). In 2007, the fraction of doctoral programs in Mathematics, Science and Technology were about $45 \%$, against $55 \%$ in China and $60 \%$ in France.

The age distribution of graduates awarded with the $\mathrm{PhD}$ title between 2002 and 2009 is shown in Fig. 1. Remember that people awarded with a PhD in 2006 were enrolled in the old system, before the implementation of the Bologna process. It is encouraging to see that in the recent years doctoral candidates graduate at a younger age.

The offer of Italian doctoral programs was quite fragmented in the past. In the academic year 2006/2007 there were about 2241 different titles of $\mathrm{PhD}$ courses, but only 30 titles collected more than 100 doctoral candidates at a national level. So, doctoral schools were born: (i) to ensure the necessary critical mass to the smooth functioning of the doctoral programs; (ii) to allow an easier coordination of interdisciplinary and inter-sectorial activities; (iii) to offer greater job opportunities for doctoral candidates through close relationships with the economic/productive system. They had a quite good diffusion nationwide. Clearly, Doctoral schools have also been effective on the internationalization issue, by promoting international agreement, thereby facilitating the integration of doctoral students in broader and qualified environments. This requires a strong economic support. And Italy suffers, compared to other countries, of a low investment in Research and Development, both in the public and the private sector.

The need to overcome all these criticality has prompted a new Ministerial Decree for doctoral training which became operational in February 2013. The main points of the Decree are:

\footnotetext{
${ }^{22}$ The graduation rates in a given year are defined as the fraction of the population between 25 and 34 year old that has been awarded with the $\mathrm{PhD}$ title.
} 
- the doctoral program duration is equal to three years;

- universities can activate industrial doctoral programs, dedicating a share of available positions to private sector employees engaged in research based activities;

- the scientific board of the doctoral program is responsible for the design and implementation of the program;

- doctoral programs can be organized in doctoral schools for the purpose of the coordination and management of common tasks;

- the call for enrolment in a doctoral program is written in Italian and in English and advertised, among other things, on Euraxess;

- admission to a doctoral program takes place on the basis of a selection of public evidence that must be completed by September 30 of each year;

- the title is awarded after the defence of the thesis in a public discussion of the findings of the research carried out during the program. The admission to this discussion takes place as a result of a positive assessment of the thesis by at least two highly qualified experts, belonging to institutions different from the one issuing the title;

- The scholarship lasts three year and shall be renewed provided that the student has completed the program of activities planned for the previous year. The fellowship amount is increased to a maximum of $50 \%$, for not more than 18 months, if the doctoral candidate is authorized to carry out research activities abroad. Moreover, in addition to the scholarship and from the second year, it is secured to each doctoral candidate a budget for its research activity in Italy and abroad to an amount not less than $10 \%$ of the awarded fellowship;

- the doctoral program involves a unique, full-time commitment, but with the possibility of a specific discipline for public employees;

- doctoral students can provide - without an increase in scholarship - tutoring and teaching activities within the limit of $40 \mathrm{~h}$ for each academic year.

From Academic year 2014/2015, doctoral programs need to be accredited ex-ante by the National Agency for the Evaluation of University and ResearchANVUR. The accreditation criteria are as follows:

- Doctoral programs can be accredited for those institutions that develop specific, wide, original, qualified and continuous activity, both in teaching and in research, adequately recognized at international level in the areas of interest for the doctorate.

- The scientific board of the doctoral program consists of at least sixteen members.

- The members of the scientific board must be active researchers in the fields of interest for the doctoral program, with documented research results at international level achieved in the five years preceding the date of request for accreditation.

- The availability of an average number of at least six scholarships for the doctoral programs activated by a university, and in any case not less than four for any single program. 
- The availability of adequate and stable funding for the sustainability of the programs, with specific reference to the availability of scholarships and the support to doctoral candidate research.

- The availability of specific and qualified operational and scientific structures for the research activity of the doctoral candidates.

- The planning of disciplinary and interdisciplinary training, the provision of foreign language and computer courses, as well as, courses in the field of management of research, knowledge of the European research systems, exploitation of research results and intellectual property.

- the presence of documented scientific activity of the doctoral students in the three years of their doctorate programs and, as PhD holders, in the following three years.

ANVUR has concluded the process of accreditation for the 2014/2015 doctoral programs. The number of doctoral programs submitted for accreditation was 903 , 883 of which were accredited. Here below there are some statistical information about the Italian doctoral programs. Let's start from the distribution of the doctoral programs among the different scientific areas. The distribution of doctoral programs for scientific macro-areas is shown in Fig. 2, which shows a prevalence of programs in science and technology $(65 \%)$ with respect to the programs in humanities and social sciences $(35 \%)$.

The contraction from 2241 doctoral programs (2006/2007) to 913 (2013/2014) to $883(2014 / 2015)$ goes in the direction of concentrating resources on programs that ensure critical mass and quality in the research environment. An evaluation ex-post is necessary to verify these statements and to complete the analysis. Such an evaluation is foreseen by ANVUR in three years time for the programs that started in 2014/15. The absolute number of declared international doctorates, industrial doctorates or doctorates in collaboration with foreign universities/enterprises is still small, although it represents about $13 \%$ of the total number of doctoral programs (see Fig. 3).

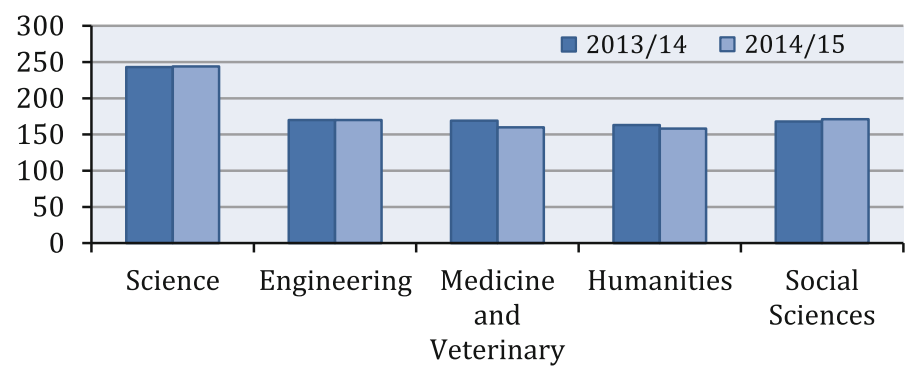

Fig. 2 Comparison of doctoral programs activated in the academic years 2013/14 and 2014/15 per scientific group. Data from the National Agency for Evaluation of the Universities and Research 


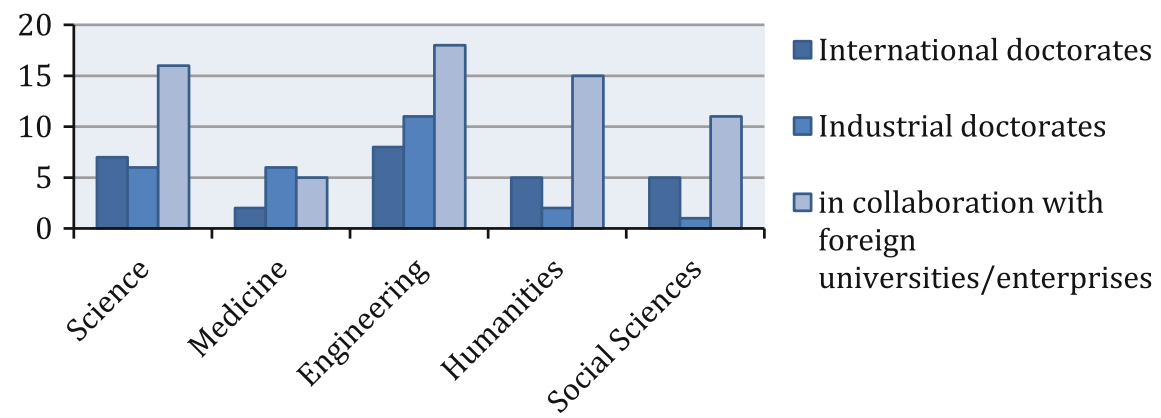

Fig. 3 Number of international and industrial doctoral programs together with those activated in collaboration with foreign universities/enterprises for the academic year 2014/15. Data from the National Agency for Evaluation of the Universities and Research

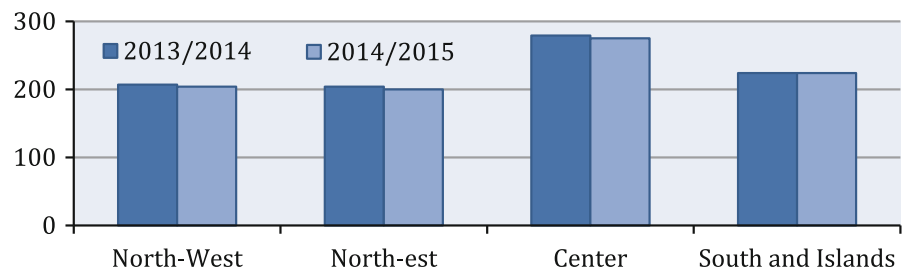

Fig. 4 Number of doctoral programs activated in the academic year 2014/15 in different regional macro-areas. Data from the National Agency for Evaluation of the universities and Research

The geographical distribution of the 2014/15 doctoral programs is shown in Fig. 4: $45 \%$ of the doctoral programs are offered in the North of Italy, $30 \%$ in the Centre and $25 \%$ in the South and in the Islands.

It is finally worth mentioning the effort for incentivizing international mobility. Even in a period of very strong contraction of the financial resources, most of the universities have allocated specific resources for further doctoral candidates to spend an amount of their time abroad. Again, this will have to be monitored and actually constitutes one of the parameters ANVUR will use to evaluate doctoral programs.

\section{Conclusion}

A doctoral program is the more valuable segment of tertiary education, where doctoral candidates are trained to research through research. Increasing its dissemination means on the one hand improving human capital and, on the other hand, providing tangible investments in research, in line with the path taken by the Commission and the European Union, first with the Lisbon Agenda, then with 
Europe 2020. The reflection that started in Europe more than a decade ago on the meaning of doctoral education has provided converging guidelines that consider quality, transparency, mobility and employability as indispensable elements of a modern and innovative doctoral program.

Doctoral programs are an integral part of the EHEA, as well as an integral part of the ERA. They function as connectors between the two European Areas - that of High Education and that of Research — and in this sense their role is - and will beeven more important than in the past. Decision makers in the EHEA and decision makers in ERA should consider the need of a more effective collaboration and of converging guidelines, developed together with High Education Institutions, to exploit the unique role that doctoral programs play between high education and research.

Doctoral programs must form human capital of high quality, of interest not only for the universities and the public research institutions, but, also for the public administration and the private-sector. In this line, the opportunities arising from a closer collaboration between the academic and non-academic sectors must be incentivized, if doctoral programs must act as a spur to research and innovation aimed to have a society which will be more and more knowledge-based.

Open Access This chapter is distributed under the terms of the Creative Commons Attribution Noncommercial License, which permits any noncommercial use, distribution, and reproduction in any medium, provided the original author(s) and source are credited. 